\title{
Preparation of Activated Carbon by Agricultural Straw and Study on its Performance
}

\author{
Yao $\mathrm{Fu}^{1}$, Yinggang Wang $^{2}$ \\ ${ }^{1}$ College of Energy and Water Resources, Shenyang Institute of Technology, Fushun, 113122, \\ China \\ ${ }^{2}$ Shenyang University, Shenyang 110044, China
}

Keywords: straw, activated carbon, adsorption performance, methylene blue.

\begin{abstract}
The activated carbon is a kind of adsorbents which has ample internal pore structure and high specific surface area, widely applying on chemical industry, pharmaceuticals, metallurgy industry, agriculture and environmental protection. The effects of operation parameters such as impregnation ratio, activation temperature and time on the adsorption properties of activated carbons,and burning time were measured and analysed in order to optimize these operation conditions. We can make such conclusions: The optimum technological conditions of preparation by chemical activation were: $\mathrm{KOH} / \mathrm{ZnCl} 2$ was the better activator, activator $\mathrm{ZnCl} 2 \mathrm{mmol} / \mathrm{L}$, solid/liquid $1: 1 \mathrm{~g} / \mathrm{mL}$, soaking time $1.0 \mathrm{~h}$, soaking temperature $20^{\circ} \mathrm{C}$, pyrolysis temperature $550^{\circ} \mathrm{C}$, the optimum washing temperature $90^{\circ} \mathrm{C}$.
\end{abstract}

\section{Introduction}

With the improvement of people's linving standard in our country, environmental problems also rise sharply. Adsorption method is widely used, as a kind of waste water and gas pretreatment method [1].In numerous adsorbents, activated carbon [2] is a good choice. China is an agricultural country, so its crop straw resource is very rich in it. There are plenty of rest straw biomass except for return to the field [3].In recent years, crop straw burning phenomenon becomes more and more serious, and it has caused to great harm for environment. Using maize straw preparation of activated carbon [4], not only can solve the problem of a large number of corn straw comprehensive utilization, but also improve the resource utilization. This experiment used straw as its raw material [5], the adsorption value of methylene blue solution and the activated carbon yield as its measurement index. First screening of activator, then explore effective activator by changing solid-liquid ratio, activation time, activation temperature, pyrolysis time and other factors[6],perfect the preparation technological parameters of chemical activation method. This article also discusses the adsorption performance of straw activated carbon, provides the technically feasible reference.

\section{Materials and methods}

\section{Materials}

Corn stover

Instrument: Multi-parameter electrochemical analyser (DR 5000 type), electronic balance (AUY220 type), oven oscillator (CHA-S type), temperature controller (KSW-4D-11 type), electrothermal constant temperature water bathpot (DK-S24 type), ultrasonic cleaner (KQ-250DB type).

Reagent: 37\% hydrochloric acid solution, 98\% sulfuric acid solution, methylene blue(A.R), potassium hydroxide(A.R), sodium hydroxide(A.R), phosphoric acid(A.R), zinc chloride(C.P) .

\section{Experimental method}

Dipping and activating the corn straw by adding activator such as inorganic salt (eg. $\mathrm{H}_{2} \mathrm{SO}_{4}$ 、 $\mathrm{ZnCl}_{2} 、 \mathrm{H}_{3} \mathrm{PO}_{4}$ ), then carbide it in a certain temperature. Activated carbon could be got by cativating finally. Because the influencing factors are different, such as the carbonization time, 
activation temperature [7], activation time and activator concentration, it could be get activated carbon of different pore-size ranges. Put the corn straw into the stoving chest after grinding it (105 ${ }^{\circ} \mathrm{C}, 24 \mathrm{~h}$ ), weight $1 \mathrm{~g}$ straw and adding some activator. Put it into the high temperature tubular resistance furnace [8], control the condition: heating rate $20^{\circ} \mathrm{C} / \mathrm{min}$, pyrolysis temperature 450 $700^{\circ} \mathrm{C}$, pyrolysis time $0.5-2.0 \mathrm{~h}$.

Protect the experimental process by controlling the N2 [9] flow rate at $0.1 \mathrm{~m} 3 / \mathrm{h}$. The production has been cleaning in turn by $3 \mathrm{~mol} / \mathrm{L}$ hydrochloric acid solution, $70{ }^{\circ} \mathrm{C}$ distilled water till $\mathrm{pH}$ is $6-7$, ultrasonic cleaner(50W,10min).Put the sample into dying oven at $120^{\circ} \mathrm{C}$ for 5 hours, grinding and get the final production through 200 mesh sieve.

\section{Results and Discussion}

\section{Effect of Activation temperature}

Put the corn straw into the oven after grinding it, and the experimental condition is: activation time 1.0h, $\mathrm{ZnCl} 25 \mathrm{~mol} / \mathrm{L}, \mathrm{KOH} 5 \mathrm{~mol} / \mathrm{L}, \mathrm{ZnCl} 2 / \mathrm{KOH}=1 / 1$,adsorption time $0.5 \mathrm{~h}$. Then it could be get the effect of activation temperature from graph 1.As a result, temperature effect on the performance of the activated product is obviously, and the best activation temperature is $20^{\circ} \mathrm{C}$.

Table 1 Effect of activation temperature

\begin{tabular}{c|c|c}
\hline $\begin{array}{c}\text { Activation } \\
\text { temperature }\left({ }^{\circ} \mathrm{C}\right)\end{array}$ & Yield (\%) & $\begin{array}{c}\text { Methylene blue adsorption } \\
\text { value(mg/g) }\end{array}$ \\
\hline 15 & 35.47 & 37.42 \\
\hline 20 & 30.83 & 38.04 \\
\hline 30 & 30.11 & 32.18 \\
\hline 35 & 28.45 & 31.33 \\
\hline
\end{tabular}

$\rightarrow$ Yield

- Methylene blue adsorption value

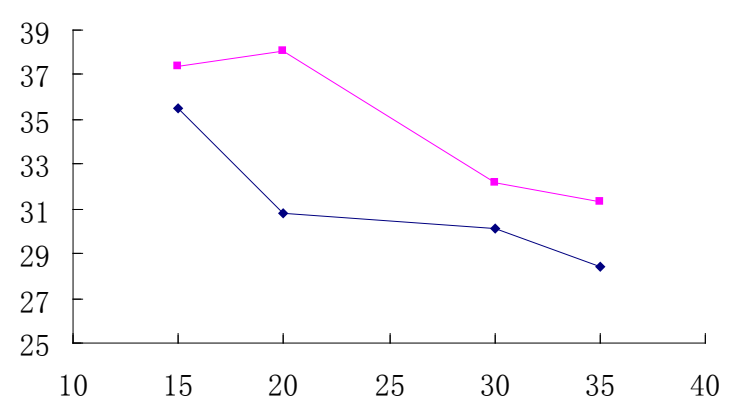

Fig. 1 Effect of Activation temperature

$\rightarrow$ Yield

- Methylene blue adsorption value

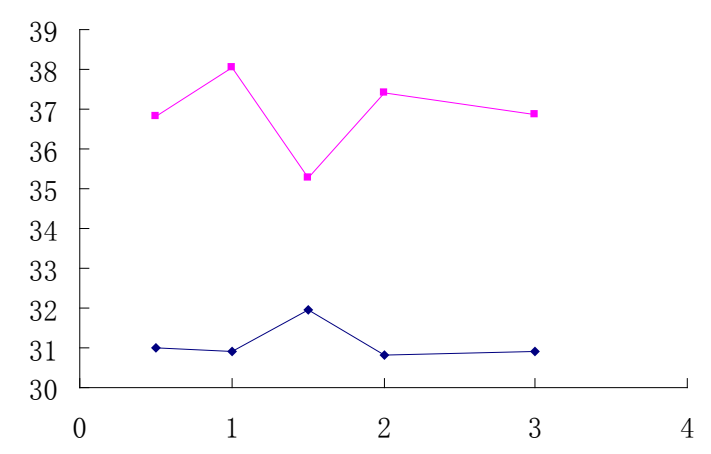

Fig. 2 Effect of Activation time 


\section{Effect of Activation time}

The experimental condition is: solid-liquid ratio $1 \mathrm{~g} / 4 \mathrm{~mL}$, activation temperature $20{ }^{\circ} \mathrm{C}, \mathrm{ZnCl} 2$ $5 \mathrm{~mol} / \mathrm{L}, \mathrm{KOH} 5 \mathrm{~mol} / \mathrm{L}, \mathrm{ZnCl} / \mathrm{KOH}=1 / 1$,adsorption time $0.5 \mathrm{~h}$. Then it could be get the effect of activation time from graph 2.As a result, the best activation time is 1.0h.

Table 2 Effect of activation time

\begin{tabular}{c|c|c}
\hline Activation time(h) & Yield (\%) & Methylene blue adsorption value(mg/g) \\
\hline 0.5 & 31.02 & 36.83 \\
\hline 1.0 & 30.91 & 38.04 \\
\hline 1.5 & 31.95 & 35.29 \\
\hline 2.0 & 30.82 & 37.39 \\
\hline 3.0 & 30.90 & 36.86 \\
\hline
\end{tabular}

\section{Effect of solid-liquid ratio}

The experimental condition is: Activation temperature $20{ }^{\circ} \mathrm{C}$, activation time $1.0 \mathrm{~h}, \mathrm{ZnCl} 2$ $5 \mathrm{~mol} / \mathrm{L}, \mathrm{KOH} 5 \mathrm{~mol} / \mathrm{L}, \mathrm{ZnCl} 2 / \mathrm{KOH}=3 / 1$,adsorption time $0.5 \mathrm{~h}$. Then it could be get the effect of activation time from graph 3.As a result, the best solid-liquid ratio is $1 \mathrm{~g} / 4 \mathrm{~mL}$.

Table 3 Effect of solid-liquid ratio

\begin{tabular}{c|c|c}
\hline solid-liquid ratio $(\mathrm{g} / \mathrm{mL})$ & Yield $(\%)$ & Methylene blue adsorption value(mg/g) \\
\hline $1 / 1$ & 29.50 & 23.79 \\
\hline $1 / 2$ & 26.33 & 25.74 \\
\hline $1 / 2.5$ & 25.41 & 26.17 \\
\hline $1 / 4$ & 16.50 & 27.28 \\
\hline $1 / 5$ & 5.83 & 24.74 \\
\hline
\end{tabular}

\section{Effect of activators remixed ratio}

The experimental condition is: solid-liquid ratio $1 \mathrm{~g} / 4 \mathrm{~mL}$, activation temperature $20^{\circ} \mathrm{C}$, activation time $1.0 \mathrm{~h}, \mathrm{ZnCl} 25 \mathrm{~mol} / \mathrm{L}, \mathrm{KOH} 5 \mathrm{~mol} / \mathrm{L}$,adsorption time $0.5 \mathrm{~h}$. Then it could be get the effect of activators remixed ratio from graph 4.As a result, the best ratio is $\mathrm{KOH} / \mathrm{ZnCl} 2=1 / 1$.

$\rightarrow$ Yield

- Methylene blue adsorption value

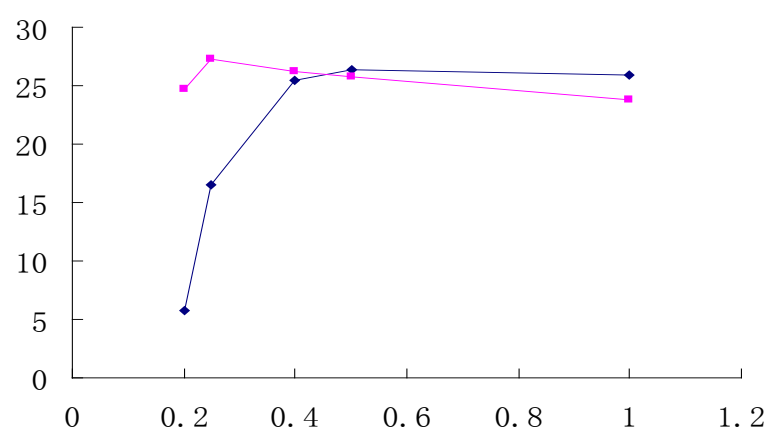

Fig.3 Effect of solid-liquid ratio 
Table 4 Effect of activators remixed ratio

\begin{tabular}{c|c|c}
\hline $\mathrm{KOH} / \mathrm{ZnCl} 2$ & Yield (\%) & Methylene blue adsorption value(mg/g) \\
\hline $3 / 1$ & 30.88 & 12.83 \\
\hline $2 / 1$ & 45.42 & 16.07 \\
\hline $1 / 1$ & 30.91 & 38.04 \\
\hline $1 / 2$ & 22.80 & 32.04 \\
\hline $1 / 3$ & 23.75 & 32.40 \\
\hline
\end{tabular}

$\rightarrow$ Yield

- Methylene blue adsorption value

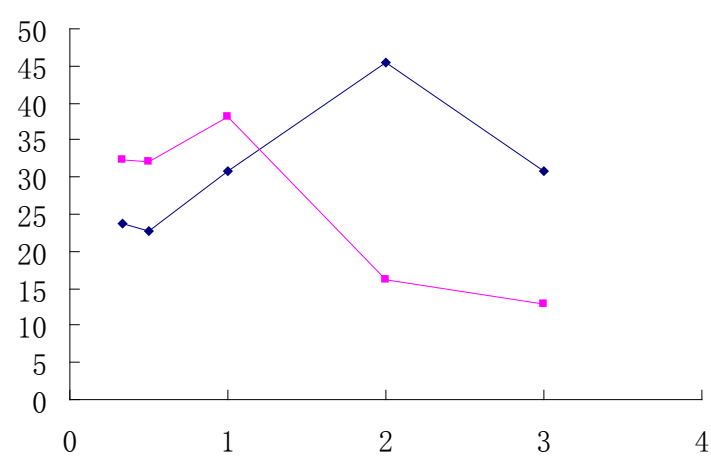

Fig. 4 Effect of solid-liquid ratio

\section{Effect of pyrolysis temperature}

The experimental condition is: solid-liquid ratio $1 \mathrm{~g} / 4 \mathrm{~mL}$, Activation temperature $20^{\circ} \mathrm{C}$, activation time $1.0 \mathrm{~h}, \mathrm{ZnCl} 25 \mathrm{~mol} / \mathrm{L}, \mathrm{KOH} 5 \mathrm{~mol} / \mathrm{L}, \mathrm{ZnCl} 2 / \mathrm{KOH}=1 / 1$, adsorption time $0.5 \mathrm{~h}$. Then it could be get the effect of activation time from graph 5.As a result, the best pyrolysis temperature is $550^{\circ} \mathrm{C}$.

Table 5 Effect of pyrolysis temperature

\begin{tabular}{c|c|c}
\hline Temperature & Yield(\%) & Methylene blue adsorption value(mg/g) \\
\hline 450 & 34.83 & 35.20 \\
\hline 550 & 30.83 & 38.04 \\
\hline 700 & 34.5 & 37.57 \\
\hline
\end{tabular}

$\rightarrow$ Yield

- Methylene blue adsorption value

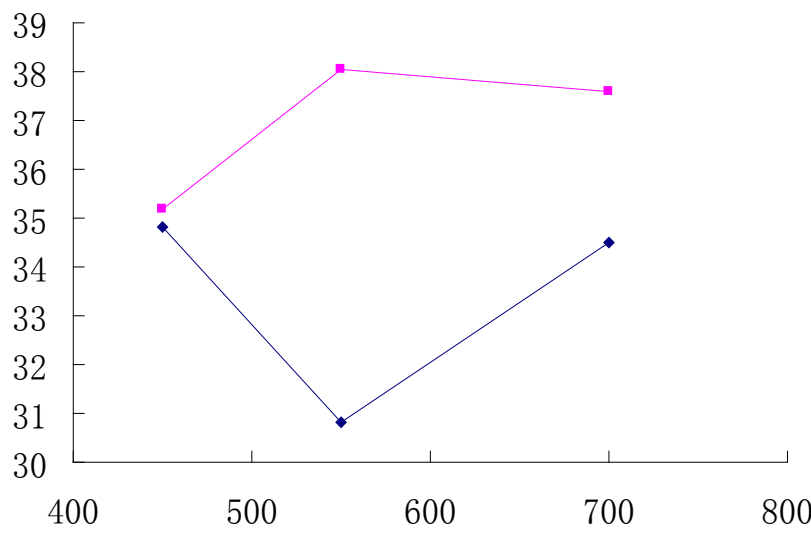

Fig. 5 Effect of pyrolysis temperature 
Talbe 6 Effect of washing temperature

\begin{tabular}{c|c|c}
\hline Temperature & Yield(\%) & Methylene blue adsorption value(mg/g) \\
\hline $25^{\circ} \mathrm{C}$ & 36.18 & 138.82 \\
\hline $40^{\circ} \mathrm{C}$ & 34.37 & 139.49 \\
\hline $80^{\circ} \mathrm{C}$ & 38.91 & 143.90 \\
\hline $90^{\circ} \mathrm{C}$ & 39.17 & 145.93 \\
\hline
\end{tabular}

\section{Effect of washing temperature}

The experimental condition is: solid-liquid ratio $1 \mathrm{~g} / 4 \mathrm{~mL}$,Activation temperature $20^{\circ} \mathrm{C}$, activation time $1.0 \mathrm{~h}, \mathrm{ZnCl} 25 \mathrm{~mol} / \mathrm{L}, \mathrm{KOH} 5 \mathrm{~mol} / \mathrm{L}, \mathrm{ZnCl} 2 / \mathrm{KOH}=1 / 1$, pyrolysis temperature $550{ }^{\circ} \mathrm{C}$. Then it could be get the effect of activation time from graph 6.As a result, the best washing temperature is $90^{\circ} \mathrm{C}$.

$\rightarrow$ Yield

- Methylene blue adsorption value

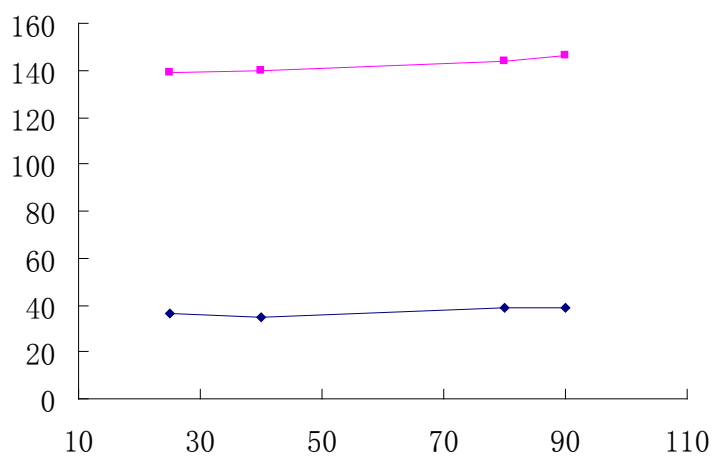

Fig. 6 Effect of washing temperature

\section{Concluding remarks}

In This experiment, Methylene blue adsorption value by corn straw activated carbon is used as the measure standard. It could be get the best process condition: $\mathrm{ZnCl} 2$ and $\mathrm{KOH}$ as the activators, Activation temperature $20^{\circ} \mathrm{C}$, activation time $1.0 \mathrm{~h}, \mathrm{ZnCl} 25 \mathrm{~mol} / \mathrm{L}, \mathrm{KOH} 5 \mathrm{~mol} / \mathrm{L}, \mathrm{ZnCl} 2 / \mathrm{KOH}=1 / 1$, solid-liquid ratio $1 \mathrm{~g} / 4 \mathrm{~mL}$, pyrolysis temperature $550{ }^{\circ} \mathrm{C}$, washing temperature $90^{\circ} \mathrm{C}$. It could be satisfid the satae provisions and requirements, by using activated carbon which prepared with agricultural straw. And because of the economic and feasible preparation technology, this product will have a broad application prospects.

\section{References}

[1]Xue-yan Li,Nai-yun Gao.Activated carbon adsorption performance in the actual application of water treatment technology.City water supply and drainage,36(5),pp.1-6,2010.

[2]Cun-lan Zhang.Biomass combustion by-products for making experimental study of active carbon.Inner Mongolia Agricultural Science and Technology, 2010.

[3]Bing-xin Bian,You-cai Zhao.Agricultural processing and comprehensive utilization of solid waste.Chemical Industry Press,2005.

[4]Lu-jia Han,Qiao-juan Yan.Crop straw resources and utilization in China.Journal of agricultural engineering,18(3),pp.87-91,2002.

[5]Yan-hua Lai,Ming-xin Ma.Straw biomass pyrolysis rule under the temperature programm. 
Combustion science and technology,7(3),2001.

[6]Dao-ping Chen.Chemical effect on the straw combustion.Hebi vocational and technical college, 3(10), 2007.

[7]Quan-qing Wang,Rui-feng Qin.Research of maize straw activated carbon prepared with phosphoric acid method.Shandong university of science and technology,(4),2003.

[8]Qiu-sheng Zheng,Long Li,Xue-yu Hu.Research of the activated carbon preparation with crop straw. Xi'an engineering university, 18(3), pp. 69-82, 2010.

[9]Li-bo Zhang,Jin-hui Peng,Jian-hua Tu.Zinc chloride activation rod manufacturing research and pore structure characterization of activated carbon. Carbon technology, 24(3), pp. 14-19, 2005. 